Revista Iberoamericana, Vol. LXXVIII, Núm. 241, Octubre-Diciembre 2012, 783-803

\title{
GRANDEZA MEXICANA: ECONOMÍA Y ONTOLOGÍA EN EL DESARROLLO TECNOLÓGICO COLONIAL ${ }^{1}$
}

\author{
POR \\ IVONNE DEL VALLE W. \\ University of California, Berkeley
}

Ángel Rama señalaba que la obra de Bernardo de Balbuena (1567-1627) era producto de la fantasía y no de una imitación realista, y que su poesía refería a un universo sólo conquistable fuera de los límites de la realidad histórica (13-15). Para José Pascual Buxó, por el contrario, la singularidad del poema Grandeza mexicana (1604), radica precisamente en el carácter realista de su tema: "Ningún otro poema 'heroico'”, dice, "había...tomado por asunto, no ya los hechos faustos o infaustos de un varón esforzado, sino la febril actividad de un abigarrado conjunto social unido, sobre su radical disparidad, por una misma razón económica” (193). Si para Rama la poesía de Balbuena apuntaba a un más allá de su entorno histórico, para Pascual Buxó en cambio, hay un desplazamiento de la heroicidad fantástica a favor de la actividad económica cotidiana.

Más recientemente, Osvaldo Pardo ha demostrado que Grandeza Mexicana está influenciada por el pensamiento de Giovanni Botero, estadista jesuita para quien el comercio y el arte eran las actividades que engrandecían la vida "material, espiritual y política" de las ciudades (106). ${ }^{2}$ Para Botero lo que llevaba a hombres dispares a concurrir en un mismo sitio era no una autoridad -fuera ésta del tipo que fuera- sino la utilidad buscada por todos en el trabajo (Pardo 106). A decir de Pardo, estas ideas constituyen el eje "estético e ideológico" del poema de Balbuena (104).

La lectura de Pardo permite ver de otra manera la aseveración de Rama respecto a la extemporaneidad de la poesía de Balbuena en relación a la historia. Se puede decir que en Grandeza Mexicana no se habla de una realidad que salga de la historia, como señalaba Rama, sino por el contrario, de la realidad posible a partir del funcionamiento de una economía que iba a modificarla y transformarla. Es decir, el poema trata de una

1 Este trabajo representa una ampliación de mi presentación “Grandeza mexicana: agua y mercantilismo en la formación del estado colonial”, presentada en CASO en Junio del 2007.

2 Véase sus obras On the Greatness of Cities (1588) y The Reason of State (1589) que Osvaldo Pardo ubica en la tradición anti-maquiavélica italo-española. 
nueva historia no determinada por factores claramente "históricos” (guerras, héroes, sucesos importantes), sino por la aparente inocencia de un sistema económico que

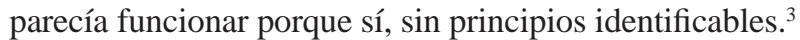

En el territorio de la antigua México-Tenochtitlan habían ocurrido ya dos transformaciones importantes a partir del "encuentro” de los dos mundos. La primera, con la destrucción de la conquista que arrasó con la ciudad y aniquiló a un alto número de sus habitantes; la segunda, con el intento de fundar un estado colonial español basado en la hegemonía a través de la creación de instituciones que dieran orden y administraran lo conquistado. El poema de Balbuena señala un tercer momento relacionado con el desarrollo de un orden económico que a pesar de haber sido instaurado por el estado colonial español, lo rebasaba.

Esta situación hace pensar en la ciudad de México como una nueva heterotopía: la formación de un "lugar otro" no sólo respecto a España, ${ }^{4}$ sino incluso respecto a la primera ciudad de México fundada a nombre del urbanismo renacentista y el estado colonial español (del Valle). Esta ciudad de México determinada por la economía y no por un poder estatal, se encuentra claramente delineada en Grandeza Mexicana, poema en el que sin embargo, también están planteados los excedentes (ontológicos e históricos) que amenazaban el desarrollo económico: los indios y el agua de los lagos en que se encontraba asentada la ciudad y que servía, como dice el mismo Balbuena, de “espejo” a la ciudad. ${ }^{5}$ En este artículo me propongo conectar el pensamiento de Balbuena respecto a estos excedentes perturbando el orden económico, con la tecnología que tres años más tarde a la publicación del poema, iniciaría a administrar los recursos (acuíferos, humanos) de la ciudad de México.

Aunque no existe entre ellos ninguna conexión directa, de forma imprevista, el canal del desagüe iniciado en 1607 para sacar el agua de las lagunas que tantos problemas causaba al cabildo de la ciudad de México, ${ }^{6}$ representa la solución técnica (y aséptica) a

3 Balbuena dice por ejemplo que México era resultado de "un parto", proceso natural desligado de la historia. Barbara Fuchs y Yolanda Martínez-San Miguel analizan las consecuencias del mercantilismo celebrado en el poema y concluyen que Grandeza mexicana muestra que las redes comerciales del imperio ibérico implican un modelo que rebasa con mucho lo transatlántico y se acerca más a la globalización, sobre todo por las conexiones entre Asia, Europa y América iniciadas en este periodo.

4 Según Michel Foucault, de quien tomo el concepto, muchas colonias fueron creadas con la intención de formar un lugar ideal respecto al "desorden” de la metrópolis de la cual provenían los colonizadores.

5 Los mexicas fundan Tenochtitlan en 1325 en una isla rodeada por seis lagos interconectados que eran, de norte a sur: Zumpango, Xaltocan, San Cristóbal, Texcoco, Xochimilco y Chalco. En este mismo sitio fundan los españoles la ciudad de México luego de la conquista en 1521.

6 Desde mediados del siglo Xvi las inundaciones fueron un problema constante en la ciudad de México. Algunas de ellas (como las de 1604, 1607 y sobre todo la de 1629) muy graves. El desagüe fue la medida que se tomó para resolver dicho problema. Durante el porfiriato en el siglo XIX, el proyecto fue retomado y se termina entonces el así llamado "Gran Canal del Desagüe” que conectaba el viejo proyecto colonial

\footnotetext{
Revista Iberoamericana, Vol. LXXVIII, Núm. 241, Octubre-Diciembre 2012, 783-803 ISSN 0034-9631 (Impreso) ISSN 2154-4794 (Electrónico)
} 
un problema planteado en el ámbito de la poesía. En mi análisis, la tecnología utilizada en el desagüe forma parte de una economía general de administración de recursos que representa la continuación de una idea que sugería que lagos e indios eran elementos ilegibles e inasimilables a la razón económica mercantil y capitalista.

\section{EXCEDENTES DE LA ACUMULACIÓN ORIGINARIA COLONIAL}

Por ser supuestamente un panegírico a la ciudad de México, dedicado además a una mujer (el poema de un posible amor diferido a la ciudad), Grandeza Mexicana es un extraño lugar para encontrar el que es quizás el primer pronunciamiento novohispano respecto a las posibilidades abiertas localmente por el mercantilismo. En el poema, la economía, al efectuar una diferenciación social producto de actividades y consumos distintos, imprimía un orden civilizatorio ${ }^{7}$ y representaba por ello nuevas opciones de auto-formación para los sujetos. Para Balbuena, la excelencia del sistema económico iniciado con la colonización radicaba en que su potencia no estaba condicionada por la realidad sino que, por el contrario, éste tenía la capacidad para rebasarla y transformarla. La diversificación laboral y la constitución de sujetos que por esa vía trascendían sus contingencias históricas representaban desarrollos que hacían factible cualquier cosa.

En el ambiente urbano de la ciudad de México, decía Balbuena, el ser humano podía dar rienda suelta a su capricho, su creatividad. Para dar un ejemplo de las promesas de dicho sistema cito los siguientes versos en los que las opciones se expanden hasta lo imposible: "Pida el deseo, forme variedades/De antojo el gusto, el apetito humano/ Sueñe goloso y pinte novedades/Que aunque pida el invierno en el verano,/Y el verano y sus flores en invierno,/Hallará aquí quien se las dé a la mano” (49). Es desde la agitada novedad de una economía que se atribuía la capacidad de modificar procesos y fenómenos naturales, que Balbuena escribe este extraño poema que se proponía alabar a México y que termina, en cambio, ofreciendo un homenaje al mercantilismo.

Este sistema económico garantizaba un régimen jerárquico constituido por dos órdenes visuales opuestos, pero complementarios. Por un lado se encuentra un acercamiento fetichista para el cual, la ciudad de México no era sino un fluir constante de actividad y de objetos que no permitían la reflexión, ni el descanso o la fijación de

a uno nuevo diseñado para sacar completamente de la región el agua del lago de Texcoco. Ver Agostini. Desde entonces, una de las labores públicas de los gobiernos locales de la ciudad de México y los estados aledaños ha sido el mantenimiento y la expansión del drenaje profundo que saca el agua (aguas residuales y lluvia, indiscriminadamente) y la tira en el Golfo de México.

7 Pardo señala esto mismo sin vincularlo con la realidad local novohispana. Barbara Fuchs y Yolanda Martínez-San Miguel señalan que la propuesta del poema de Balbuena desestabiliza el orden estamental hispánico (686).

Revista Iberoamericana, Vol. LXXVIII, Núm. 241, Octubre-Diciembre 2012, 783-803 ISSN 0034-9631 (Impreso) ISSN 2154-4794 (Electrónico) 
la mirada. Se tratara ya de obras arquitectónicas, de objetos, mercancías, medios de transporte, o bien de sus mismos habitantes, la ennumeración que de ellos hace Balbuena les confiere el ritmo acelerado de su época:

Como en estos caminos y calzadas

En todo tiempo y todas ocasiones,

Se ven gentes cruzar amontonadas.

Recuas, carros, carretas, carretones,

De plata, oro, riquezas, bastimentos

Cargados salen, y entran a montones. (25)

O bien,

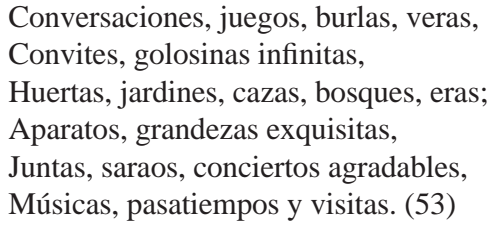

La aglutinación aparenta estar determinada por la realidad de una ciudad a la que se enfrenta un espectador para quien el sentido de lo visto queda postergado para un momento de quietud y lejanía nunca alcanzado en el poema. Desde su persistencia, objetos y actividades se imponían categóricamente agotando en sí mismos todo su significado: la ciudad no era nada sino lo visto y lo visto era la totalidad de la ciudad.

Pese a la actividad incesante, Fernando Gómez ha llamado la atención sobre el vacío de México, su carácter deshabitado en el poema (543). En Balbuena, la ciudad aparece repleta: mucho que ver, mucho que hacer, el sinnúmero de objetos transportados por sus calles, pero un sitio sin gente al fin y al cabo. Y no es que los seres humanos estén ausentes del poema, sino que cuando aparecen su presencia tiene el mismo carácter que el resto de los objetos y actividades mencionados. Son parte constitutiva e indiferenciada de la acumulación paratáctica de objetos, ocupaciones, personas y actividades. Cuando están presentes son transformados ya sea en los objetos que producen o los instrumentos que utilizan (“telas”, “vasos”, "esculturas”, "pincel”, "buril”, "moldes”), o reducidos, contenidos en el nombre de la actividad que realizan ("hilanderos", "plateros", "lapidarios" [43-44]). México es así el guión de una actividad obligada, tan indiferente al lado humano que pasaría a representar papeles otorgados de antemano, como al contexto material de su existencia. En este sentido, el ritmo de la ciudad imponía una conducta: la serie compleja de actividades necesarias para hacer de ella un sitio de una energía excepcional en la cual el buril del escultor resultaba tan necesario e importante como su operador.

Revista Iberoamericana, Vol. LXXVIII, Núm. 241, Octubre-Diciembre 2012, $783-803$
ISSN 0034-9631 (Impreso) 
Son precisamente la indiferenciación ontológica de un universo (humano y material) subsumido en la actividad enervante de la ciudad, y la falta de fijeza en la mirada y el pensamiento, los que garantizan el ejercicio de una nueva perspectiva visual que complementa a la anterior. Por este movimiento México desplaza la primacía de la metrópoli y deviene la posición desde la cual se debía ver el resto del virreinato. Balbuena hace de esta ciudad, el lugar de la civilización y el progreso, opuesto de forma absoluta al campo, o sitios menos urbanizados, vistos como universos monótonos, todavía indiferenciados por carecer de clases sociales y por ello, de la variedad posible en una sociedad clasista: "Ser primero en el campo o ser segundo,/Tener bienes sin orden de gozallos,/Misterio es celestial, alto y profundo” (47), indica, señalando que sólo la presencia de un mercado que permitiera un consumo diferencial daba sentido a la riqueza.

Paradójicamente, puesto que Balbuena se acercaba a México desde Nueva Galicia, ${ }^{8}$ su mirada propone a la primera como el lugar absoluto cuyo sentido desdecía las "bondades" del resto del espacio colonial (la supuesta salud en el campo, por ejemplo). México es el centro, el lugar fijo, sitio de convergencia de todas las líneas. En este sentido, Nueva Galicia y el resto de las provincias no son consideradas productoras de una perspectiva legítima, sino como espacios para ser moldeados desde la experiencia central. De esta forma, en la Grandeza mexicana, México es la cifra de la verdad y la razón, opuesta a otras regiones novohispanas, pero también opuesta a la lejanía de España.

Lo que es más interesante en esta propuesta es que sea la razón económica y ningún otro factor lo que hace de México la ciudad del presente y del futuro. En el poema, México no es sino el nombre de una posibilidad económica y no una densidad histórico-cultural en la medida en que todo significado en este sentido es borrado por la territorialización del mercantilismo. Y enfáticamente no es una entidad histórica puesto que Balbuena la deslinda tanto del pasado prehispánico, como de la influencia española. Por razones estéticas -centrarse en la "belleza", dice- omite lo que él llama el "oscuro origen de naciones fieras", y deja también para otro momento la conquista, "los hechos heroicos” de los hombres que habían forzado su imperio en un nuevo territorio (30-32). En un gesto moderno, se postula el principio de otra historia, la historia en la forma de una economía que borraba las corrientes culturales e históricas que la antecedían y le daban lugar. La ciudad se originaba prácticamente de la nada, era producto de lo que él repetidamente llama “un parto", un proceso "natural”, resultado de la circulación de mercancías.

De esta forma, este poema leído muchas veces como un panegírico a la ciudad, no es sino un canto al mercantilismo que permitía a un determinado territorio ser el lugar

8 Balbuena llega a México de España en 1584 y parte muy pronto a Nueva Galicia, provincia en la que ocupa cargos eclesiásticos durante varios años en pueblos especialmente aislados y pequeños. Ángel Rama señala que es precisamente por sentirse "desterrado" a los márgenes de la civilización que Balbuena enfáticamente se "reintegra” al mundo civilizado en su poesía (14).

\footnotetext{
24) Revista Iberoamericana, Vol. LXXVIII, Núm. 241, Octubre-Diciembre 2012, 783-803 ISSN 0034-9631 (Impreso) 
para el despliegue de una energía que, una vez desligada de sus orígenes históricos, resultaba universal, cosmopolita. Es por ello que Barbara Fuchs y Yolanda MartínezSan Miguel se resisten a ver el poema como una manifestación de orgullo criollo por la ciudad (677). El ánimo exaltado que permea el poema resiste esta identificación: la ciudad y sus habitantes tenían un carácter internacional, mundano e incontaminado por regionalismos tradicionales. El tráfago de los objetos confería a la ciudad su cualidad y no a la inversa; México se desdibujaba para convertirse en el escenario neutro de una épica comercial. ${ }^{9}$ La característica principal de este México era ser precisamente el lugar de intersección, el sitio de encuentro del resto del mundo que llegaba hasta ahí en la forma de mercancía proveniente de Perú, Chile, Arabia, Cambray, Sicilia, Siria, China, India, Goa, España, Filipinas, Egipto, Roma, Milán y Flandes, entre otros (Grandeza 39-40).

En esta ennumeración se encuentra el otro efecto del regimen visual y económico que hacía converger todas las líneas en México: el hecho de que frente a la actividad de la nueva ciudad, España aparezca desplazada para ser un simple elemento más entre otros muchos en el sistema desatado por la economía. ${ }^{10}$ De hecho, Fuchs y MartínezSan Miguel han leído el poema precisamente como un ejemplo de la globalización del mundo iniciada por el mercantilismo ibérico que logra conectar, utilizando a México de "bisagra”, los mercados europeos y asiáticos. Esta apreciación puede no ser exagerada si se considera que estudios recientes señalan que desde principios del siglo XVII el comercio "real" con las Indias y la obtención de beneficios por este rubro, estuvieron dominados por otras naciones (Larraz 56-57). España podía haber dado origen a una cierta economía y podía también ejercer el dominio político de los territorios, y sin embargo, el mismo sistema que impulsaba la descentraba radicalmente a nombre de la energía desatada por el comercio de mercancías y materias primas. ${ }^{11}$ Desde principios del siglo xviI, las redes comerciales iniciadas por la metrópoli y su relación con las colonias, son vistas por Balbuena como algo que rebasaba a la misma España.

En la medida en que la experiencia colonial española aportaría tanto información como importantes recursos económicos a las naciones europeas protagonistas de la segunda oleada colonialista, puede pensarse que aquella empezaba a formar parte del

9 Véase el artículo de Fuchs y Martínez-San Miguel para un interesante estudio sobre el género del poema y la manera en que en su interior los motivos épicos se transforman en "abundancia económica” (689690).

${ }^{10}$ En el canto penúltimo, y en lo que desde mi perspectiva es un deseo tardío de anclaje, Balbuena vuelve a España y a condecerle la posesión de una Nueva España que sin embargo, había marcado como muy independiente en los cantos anteriores.

11 Opinión de nuevo certera si se considera que en gran medida los tesoros provenientes de las Indias sirvieron no para engrandecer la economía interna española, sino para pagar sus intervenciones en el extranjero (Tortella y Comín 150-151). Fuchs y Martínez-San Miguel resaltan en cambio, las oportunidades que la nueva economía representó localmente (693).

ISSN 0034-9631 (Impreso) 
proceso de acumulación primitiva de esas otras naciones. Lo obtenido por ellas de España (riqueza y saber) serviría para la consolidación del capitalismo de los nuevos poderes europeos. ${ }^{12}$

Si España es descentrada, y la historia de los indígenas y de la conquista no podían ser utilizadas para explicar el origen de esta economía, Balbuena encuentra en el “interés” (que Pardo equipara a la "utilidad” de la que escribía Botero, 106) el motor de dicho desarrollo. Para Balbuena, la creación del México-encrucijada comercial, se debía a una disposición interna del sujeto, al ejercicio de una voluntad que tenía en el interés un poderoso resorte para la acción. Detrás de las acciones de los conquistadores, del trabajo del labrador, la industria del mercader, el quehacer de pastores y escribanos, detrás de todo esto se hallaba, según Balbuena, el interés (26-29), que puede entenderse en tanto que interioridad inclinada a poseer algo del mundo. ${ }^{13}$

Balbuena señala por otro lado que quien trabajaba en la ciudad de México lo hacía siguiendo una opción propia: “Todos en gusto y en quietud dichosa”, indica, "Siguen pasos y oficios voluntarios” (44). En esto parecería adelantarse a las ideas de Marx respecto al capitalismo que requiere de trabajadores que voluntariamente ofrezcan su labor a cambio de cierta remuneración. Sin embargo, para que la gente ofreciera su trabajo para beneficio de otros, era necesaria una primera etapa, el oscuro proceso de acumulación originaria por el que se expropiaba a los trabajadores los bienes de producción cuya falta los obligaría a recurrir a otros para sostenerse (Capital 784-786). ${ }^{14}$ Es precisamente este proceso de expropiación violenta -el único evento que ligaba la historia prehispánica con el mundo colonial-lo que Balbuena elige olvidar en su poema a nombre de la estética del poema. México quedaba así libre de problemas culturales o históricos que interrumpieran el fluir de la poesía y de las mercancías. En ese sentido,

${ }_{12}$ En su discusión respecto a la piratería del conocimiento llevada a cabo por otras naciones europeas, Ralph Bauer asegura que "Spain's mercantilist economy of knowledge had ultimately benefited not Spain or Spanish America, but rather her Protestant enemies (English and Dutch pirates)” (168). La opinión de Tortella y Comín apunta en el mismo sentido aunque no en relación a la epistemología, sino respecto a la economía.

${ }^{13}$ Marx, en sus comentarios respecto al trabajo (en tanto que la esencia de la propiedad privada), señala el acierto de Engels de referirse a Adam Smith como el Lutero de la economía política en la medida en que Smith -igual que Lutero respecto al problema de la fe- transforma la concepción de la riqueza. Si para los mercantilistas, a quienes Marx llama "fetichistas” y “católicos”, la riqueza estaba supuestamente constituida por objetos desplegados en la exterioridad del mundo, para Smith, la esencia de la propiedad privada era el hombre mismo ("Third Manuscript” 290). Sin embargo, como señala Pardo respecto a la obra de Botero, y como indico aquí en torno a Balbuena, había entre los miembros del imperio español un pensamiento parecido al que encuentra Engels en Smith.

14 Oscuro porque según Marx representa el sine qua non de la economía política para la cual representa lo que el "pecado original” a la teología: una condición necesaria, pero misteriosa y perdida en la lejanía de los tiempos (Capital 784).

ISSN 0034-9631 (Impreso) 
la violencia de la conquista es el "misterio" que llevaba de la posesión de la tierra y los medios de producción que inicialmente se hallaban en manos indígenas, al ofrecimiento "voluntario" de su trabajo para sostener la mágica efervecencia de la ciudad.

Según Marx, sin embargo, en las colonias el proceso de acumulación originaria necesario al desarrollo futuro del capitalismo presentaba serios problemas debido a que ahí los trabajadores seguían poseyendo sus propias tierras o bien podían cambiar continuamente de oficios: ser campesino un día y al día siguiente zapatero, herrero, etc. -lo cual les daba cierta independencia respecto al trabajo asalariado (Capital 838848). ${ }^{15}$ Por estas dificultades, dice Marx que en las colonias resultaba necesario llevar a cabo una "colonización sistemática" (Capital 841), que puede entenderse como la serie de condiciones artificiales impuestas para garantizar la acumulación de capital.

En Balbuena, el trabajo realizado en la ciudad que, como vimos, definía a los sujetos de acuerdo a su oficio (ahí se era lapidario, escribano, escultor, etc.), podía realizar una especie de vaciado ontológico y cultural que prometía cumplir un estatuto de la colonización sistemática al equiparar al sujeto totalmente con su trabajo. El universo indígena tanto como el hispano, o el de los esclavos y otros grupos étnicos, quedaba subsumido o aniquilado por la práctica laboral llevada a cabo. Es por esto que aunque existen seres humanos en el poema, éste tiene una carácter inhabitado, deshumanizado: el trabajo desplazaba al sujeto que lo realizaba.

Pese al éxito aparente de esta colonización, hay en la obra varias excepciones respecto a este proceso. Por un lado, el indio de las fronteras con que inicia el poema; por otro, el indio tributario con el que concluye. La excepción cercando la Grandeza Mexicana representa el universo que socava a la economía. En el caso del indio fronterizo al que se alude en la introducción (el que vivía en "los más remotos confines” de la Nueva España), se trataba de una vida a la que "la naturaleza" no había podido civilizar -a diferencia de lo que había logrado el interés en la ciudad de México-;/'. Ahí, el indio era todavía un "salvaje”, una "temerosa imagen”; “espantosa figura” cuyo supuesto salvajismo era directamente proporcional a su falta de participación en la economía mercantil (15-16). En el caso del centro mismo del orden urbano se hallaba sin embargo, otro remanente.

En los últimos versos del poema aparece por fin una figura humana, la del "indio feo" con cuyo tributo se llenaban las flotas del monarca. Lo inusitado de esta presencia que trabajaba no por voluntad propia, como aseguraba Balbuena que se realizaban los oficios citadinos, sino por "gusto" y voluntad del rey, representa una extraña conclusión a la obra (93). En primer lugar porque su trabajo no-voluntario desmiente lo que había dicho inmediatamente antes: que las "bárbaras gentes" habitando dicho territorio tenían

${ }^{15}$ En su ejemplo, sobre las colonias inglesas, Marx no está pensando en los habitantes indígenas, como hago yo aquí. Sin embargo, la ambigüedad de la que habla Marx está presente en la fluidez laboral de los indígenas de la zona central novohispana que de ninguna manera dependían del trabajo asalariado para sobrevivir.

ISSN 2154-4794 (Electrónico)
ISSN 0034-9631 (Impreso) 
ya lo que él llama un "trato afable" para con el soberano (92). Por el contrario, esta inserción revela que había gente a la que se obligaba a trabajar. El hecho al que se había referido antes respecto a los españoles que con su espada habían "sujetado" más mundo del que otros pudieron entender, vuelve a surgir aquí en un inadvertido recordatorio de la fuerza que sostenía las relaciones coloniales (91).

En segundo lugar, este excedente ontológico-estético (la fealdad que dañaba la ligera construcción del poema) contraviene la domesticación ontológica del sujeto elaborada por los oficios de la urbe. Estos indios seguían siendo indios pese al trabajo. A diferencia de la manera en que en el resto del poema Balbuena se refiere a otros sujetos (indígenas o no), a estos últimos no los llama simplemente "tributarios", igual que había hecho con los "lapidarios”, “escultores”, “alquimistas”. Su trabajo no los consumía del todo, no agotaba la totalidad de su sentido. Ontológicamente rebasaban la determinación de la economía. Pese al optimismo de Balbuena, tanto en las fronteras, como en el centro mismo de la colonia existían todavía sujetos inasimilables para el orden cívico y jerárquico mercantil. En la última sección de este artículo volveré a estos excedentes de la acumulación originaria, pero antes voy a señalar otro aspecto que enturbiaba el entusiasmo del poeta, para quien lo sublime se encontraban en el avance deslumbrador de las mercancías. ${ }^{16}$

\section{EL AGUA DE LOS LAGOS, SIN EMBARGO}

En su ensayo respecto a la coexistencia de espacios disímiles e irreductibles como característica de nuestro siglo, Michel Foucault asegura que en toda cultura existen sitios reales, conformados desde la misma fundación de una sociedad, que funcionan como un "contra-espacio" respecto al universo configurado por dicha fundación. Estos sitios, dice, son una especie de utopía realizada en la que se impugnan e invierten todos los otros espacios. Foucault utiliza el nombre de "heterotopía” para referirse a estos lugares que pese a ser reales tienen una función abstracta (se relacionan con todos los demás, transformándolos) que los hace aparecer como fuera del espacio. Muchas de estas heterotopías estarían además relacionadas con distintos fragmentos de tiempo, constituyendo a la vez lo que él llama "heterocronías".

En este apartado me referiré a los lagos que rodeaban la isla de Tenochtitlan y que persistieron luego de la fundación colonial de la ciudad de México, en tanto que una heterotopía que remitía a otro tiempo y otra sociedad, cuestionando la plenitud del espacio colonial novohispano. Tal es, como veremos, la ambigua función de los lagos

${ }^{16}$ Fernando Gómez indica que la escritura de Balbuena está motivada por la búsqueda de una mejor posición social. La literatura misma estaría así definida en términos económicos en la medida en que puede ser la causa de una mejor posición social, y es por lo tanto una especie de objeto de intercambio.

\footnotetext{
Revista Iberoamericana, Vol. LXXVIII, Núm. 241, Octubre-Diciembre 2012, 783-803 ISSN 0034-9631 (Impreso)

ISSN 2154-4794 (Electrónico)
} 
en el poema de Balbuena, pese a los esfuerzos de éste por contenerlos dentro del viejo tropo mercantil en el que el agua es simplemente un eficaz medio de transporte.

En Grandeza mexicana, el agua, sustraída del complejo hidraúlico de fabricación prehispánica del que formaba parte, ${ }^{17}$ es el medio que permitía el fluir mercantil que hacía de México un sitio axial en el nuevo orden económico:

Cruzan sus anchas calles mil hermosas
Acequias que cual sierpes cristalinas
Dan vueltas y revueltas deleitosas,
Llenas de estrechos barcos, ricas minas
De provisión, sustento y materiales
A sus fábricas y obras peregrinas
[...] Entra una flota y otra se despide,
De regalos cargada la que viene,
La que va del precio que los mide. $(26)^{18}$

En estos versos el agua de los canales prehispánicos y las canoas que los surcaban tienen funciones semejantes a las del mar y los barcos que a partir de la época de exploración han representado la posibilidad del desarrollo económico debido a la explotación de sitios repletos de una riqueza desconocida.

Esta plácida evocación de un transcurrir sin problemas se asemeja a las imágenes contrastantes utilizadas por Frantz Fanon para referirse a la relación dialéctica entre metrópoli y colonias a las que une y separa un mar que siendo el mismo es simultáneamente, desde la realidad que se vive en cada orilla, dos mares absolutamente distintos. Dice Fanon que los puertos de la metrópoli son un espacio de tranquilidad, de imágenes idílicas contrastando con la invisibilidad de las playas de las fiebres y la malaria al

${ }^{17}$ En la época prehispánica y debido a condiciones climáticas y geográficas específicas (el agua de tres de los lagos era salada y la región lacustre se encontrara en una depresión central sin salidas al exterior) el control del agua se llevaba a cabo mediante un complejo sistema para proteger a la ciudad y los sembradíos flotantes (chinampas) de posibles inundaciones. Era también importante asegurar suficiente agua para consumo humano a través de la construcción de acueductos. Dentro de la ciudad había un sistema de acequias y canales cuya cantidad de líquido era controlada a través de compuertas, para asegurar agua para las canoas. La ciudad estaba conectada a tierra firme a través de amplias calzadas construidas sobre el agua, algunas de ellas midiendo más de 9 kilómetros. Había también albarradones (el más largo de 16 kilómetros) que, además de proteger de inundaciones, tenían varias funciones como controlar los niveles de agua dentro de la ciudad y separar el agua fresca de la salada. En el siglo xvI México-Tenochtitlan era una ciudad semi-acuática con algunas calles sólo de agua, otras calles sobre tierra y algunas más mixtas: mitad en tierra y mitad en agua.

${ }^{18}$ Pardo señala que en su obra respecto a la grandeza de las ciudades, Botero alaba el agua (y el mar especialmente) por ser un excelente medio para el comercio. Como indica Pardo, Botero se refiere explícitamente a la ciudad de México y su lago, dato que evidentemente no pasó desapercibido para Balbuena (106-107).

ISSN 0034-9631 (Impreso) 
otro lado del océano (51). En la ciudad de México, sin embargo, esta conveniencia visual que escatimaba la imagen del otro lado, no era posible. De la misma manera en que el trabajo real era absolutamente visible en sujetos que no podían ser consumidos totalmente por su calidad de tributarios (los "indios"), la naturaleza verdadera del agua circulando por la ciudad de México no podía pasar desapercibida para Balbuena pese al tropo renacentista con que la presentaba. Si a diferencia del modelo de Fanon, Balbuena no tenía frente a sí una playa de fiebres y malaria que se opusiera a la complaciente imagen del lago y los canales por los que llegaban a la capital novohispana las materias primas y las mercancías, sí tenía en cambio un acertijo, el representado por el sistema hidráulico de creación indígena que los españoles nunca llegaron a comprender o a saber manejar (Palerm 353).

En algunos versos Balbuena aseguraba que del paisaje semi-acuático de la antigua Tenochtitlan poco quedaba en México:

Y admírese el teatro de fortuna,

Pues no ha cien años que miraba en esto

Chozas humildes, lamas y laguna;

Y sin quedar terrón antiguo enhiesto,

De su primer cimiento renovada

Esta grandeza y maravilla ha puesto. (90)

Si por un lado, según Balbuena la laguna y las chozas de los indios habían sido reemplazadas por la "gran" ciudad, las frecuentes inundaciones durante la temporada de lluvias y el silencio indígena ante las peticiones del cabildo solicitándoles ayuda para saber cómo manejar el sistema por ellos construido, debían ser un recordatorio del endeble fundamento de la "grandeza" de la ciudad de México (del Valle). En este sentido, el agua tenía una importante función respecto a la ciudad colonial fundada en ella: servía como un espejo que a la manera de las heterotopías especulares analizadas por Foucault, devolvía a México una imagen distorsionada, irreconocible de sí misma. El agua persistía y las técnicas implementadas por los españoles para controlarla resultaban del todo inadecuadas; el urbanismo de la ciudad que maravillaba a Balbuena se detenía ante un agua que no sabía manejar.

Así pues si el agua de los lagos es utilizada por Balbuena como un medio fundamental para el funcionamiento del mercantilismo, por otro lado, el exceso de agua durante cada temporada de lluvias, demostraba que ésta no era la suave superficie sobre la que se deslizaban las naves cargadas de riquezas, sino una potencia devastadora que continuamente amenazaba con tragarse a la ciudad.

Si el interés es un leitmotiv en el poema, la naturaleza semi-acuática de la ciudad es otro. Gómez ha señalado que Grandeza Mexicana es un poema todo ligereza y superficie

\footnotetext{
Revista Iberoamericana, Vol. LXXVIII, Núm. 241, Octubre-Diciembre 2012, 783-803 
(545). Si bien esto es cierto ya que no hay en el poema el menor atisbo crítico o reflexivo en torno a sus temas y acercamiento, también lo es que Balbuena parece darse cuenta que el resultado de tantas mercancías y tanta actividad era de una pesadez insostenible. Como repite muchas veces, la ciudad de México no se asentaba sino sobre "un delgado suelo", sobre una “delicada costra blanda”. ${ }^{19}$ De hecho, para asegurar que la ciudad no cayera bajo su propio peso, recurre a ninfas que desde la profundidad del lago multiplican cimientos en la medida en que en la superficie de la capital aumentaban los edificios:

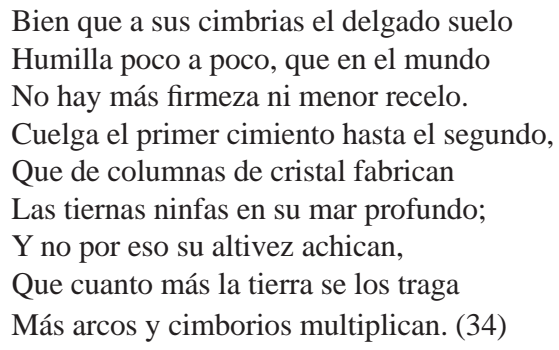

En la figura, sin embargo, Balbuena implica una batalla entre el lago y la ciudad en la que los arcos y pesadas torres de la superficie son poéticamente defendidas por frágiles columnas de cristal.

El espejo, dice Foucault, nos permite vernos donde estamos ausentes, en eso consiste su utopía: en decir que estamos del lado en donde en realidad no estamos. Sin embargo, el espejo es también una heterotopía en la medida en que es un sitio real que contraviene el espacio en que nos encontramos. El agua del lago de Texcoco es así el espejo que podía recordar a criollos y españoles que en realidad no se encontraban en la ciudad de México, sino en un espacio fundado desde mucho antes y con conocimientos que les eran ajenos: la "grandeza” mexicana se encogía ante la imagen de sí devuelta por los lagos en la que sus logros estaban constantemente a punto de venirse abajo debido a la desconexión entre formas de vida (prehispánica/hispana) que manejaban los recursos y el medio ambiente de forma desigual.

La ciudad de México que confrontaba esta imagen debía admitir que ni el agua de los lagos, ni los indios que hubieran podido manejarla prestaban "afablemente" sus servicios al mercantilismo. Por el contrario, el fracaso de las autoridades coloniales para manejar el complejo hidráulico hace pensar que el agua era todavía parte de otro sistema cuyo manejo estaba restringido a la realización de ceremonias en los que se

19 Trinidad Barrera señala que el asentamiento acuático de la ciudad es el elemento que "prioritariamente" preocupaba a Balbuena en su descripción de la ciudad (74).

Revista Iberoamericana, Vol. LXXVIII, Núm. 241, Octubre-Diciembre 2012, $783-803$
ISSN 0034-9631 (Impreso) 
invocaba a los antiguos dioses (Arnold), ${ }^{20}$ cosa que las autoridades coloniales no podían ni realizar ellas mismas, ni permitir que otros las llevaran a cabo.

Si el agua de los lagos era un espejo incómodo en el cual se reflejaba y negaba el orden de la ciudad, puede concluirse que pese a la aseveración de Marx respecto a la incapacidad de todo espacio de resistir la economía una vez que ha sido capturado por ella (“Third Manuscript” 291), seguía habiendo, al menos en este entorno colonial, áreas que aún siendo visibles eran al mismo tiempo indescifrables para la mirada y el conocimiento y por ello escapaban a la hegemonía de los regímenes visuales modernos. Este espacio que remitía también a otro tiempo, era inaprehensible para el orden cívico instaurado por la actividad mercantil.

A partir de la segunda mitad del siglo xvi la ciudad colonial sufre varias inundaciones. Una de ellas unos cuantos meses después de la escritura de Grandeza mexicana, y otra, muy grave, en 1607, momento en que las autoridades españolas deciden poner en marcha el así llamado “desagüe de la ciudad de México”, un enorme proyecto de ingeniería que fue modificándose y ampliándose a lo largo del periodo colonial para sacar el agua de los lagos de la región lacustre (Mathes, Agostoni, Aréchiga). ${ }^{21}$

Antes de vincular la tecnología del desagüe con la poesía, en una economía colonial general, quiero señalar la manera en que Balbuena trata de contrarestar la función especular de unos lagos que afirmaban otro México y otra ciudad respecto al espacio novohispano, a través de hacer proliferar en sus obras mismas espejos que resultaran más amables al desarrollo mercantil de México que el agua de los lagos.

Según Rama el formalismo es uno de los rasgos más notables en la obra de Balbuena. Especialmente en Grandeza mexicana, agrega, es evidente la manera en que el poeta, con un mecanismo que recuerda al del emblema y el epigrama, presenta dentro de su obra un modelo reducido de la misma "capaz de absorber una totalidad inabarcable en sus medidas naturales" (17-18). La cifra de toda la Grandeza se encuentra en el epílogo, donde en unos cuantos versos se presenta un modelo condensado del poema desarrollado a lo largo de ocho capítulos. Esta cifra, dice Rama, es distinta de la realidad, es invención (18), la Grandeza contiene en sí su modelo en miniatura, no requiere de ningún referente extraliterario, toda ella se encuentra dentro de sí misma en un ejercicio estético autoreferencial.

20 Philip Arnold demuestra cómo el agua de la zona, incluida la de los lagos, era manejada por los indígenas a través de una serie de rituales técnico-religiosos que articulaban y daban sentido a la ocupación mexica de la región.

${ }^{21}$ Los artículos de Michael Mathes y Ernesto Aréchiga, junto con el libro de Claudia Agostoni, presentan el panorama colonial de las inundaciones así como un análisis en torno al proyecto del desagüe en el siglo XVII. Agostoni estudia también su continuidad y expansión en el siglos XIX, y Aréchiga hace una breve reseña respecto al desagüe en el siglo xx.

Revista Iberoamericana, Vol. LXXVIII, Núm. 241, Octubre-Diciembre 2012, 783-803 ISSN 0034-9631 (Impreso)

ISSN 2154-4794 (Electrónico) 
Por mi parte, creo que la inserción de Balbuena de esta última sección, en la que retoma y condensa los capítulos de su poema, funciona a la manera de un espejo que devuelve -éste sí-la imagen de la "grandeza” de la que había venido hablando a lo largo del poema. En este sentido, el agua de la laguna y el "delgado suelo" que la separaba de México quizás explican el recurso de la cifra. Antes de presentar la imagen reducida del poema, Balbuena se pregunta: “¿Quién alborota en mí nuevos cuidados/Para cifrar lo que cifré primero/Pues todo es cifra y versos limitados?” (82). Desde mi perspectiva la respuesta se encuentra tal vez en la realidad extra-poética que obligaba a reforzar interiormente el tema y el sentido del poema.

La operación se repite años más tarde en Siglo de oro en las edades de Erífile (1608), en el que Balbuena marca claramente la relación especular entre la laguna y la ciudad que ya había sugerido en Grandeza mexicana. En esta obra el poeta emprende un viaje fantástico por el que ingresa dentro de la tierra y atraviesa un mundo maravilloso de cuevas, grutas, y estanques para descubrirse finalmente en las profundidades de una "ancha laguna" sobre cuyas ondas observa una populosa ciudad para concluir que lo visto desde el fondo del lago no era otra cosa que la "Grandeza mexicana" (133). En este segundo intento de fijación del significado (el primero en la maravilla de un México doblemente cifrado en Grandeza mexicana; el segundo en la creación de un espejo fantástico para la ciudad en el Siglo de oro), Balbuena vuelve a poblar la laguna de ninfas y musas que desplazan a los antiguos dioses del agua. Así, un año después de la inundación de 1607, que lleva a las autoridades coloniales a iniciar con el desagüe, Balbuena pone en marcha una serie de estrategias poéticas para garantizar que la visión de México desde la laguna fuera la que él había establecido años atrás en su Grandeza mexicana. Para salvar a la moderna y cosmopolita ciudad de México de la contingencia histórica-ambiental se coloca él mismo en el fondo del agua y se rodea de etéreas ninfas que lo auxilen en su recorrido. De esta manera, el formalismo de Balbuena que según Rama se encuentra en el terreno de la pura invención adquiere un carácter compensatorio respecto a la inmanejable realidad del agua de los lagos.

El DESAGÜE, O LA ECONOMÍA DE LA ECONOMÍA

En estaúltima sección analizo la relación entre los excedentes señalados por el poema de Balbuena con el desagüe, la tecnología colonial que permitiría consumir al mismo tiempo agua y seres humanos. Aunque no sugiero una relación directa entre el poema de Balbuena y la tecnología hidráulica colonial -lo que sería absurdo- sí propongo que la manera en que agua e indígenas son tratados en Grandeza mexicana es representativa. Si la tecnología nunca hace explícito el sustrato ideológico que la sostiene, y parece más bien solucionar problemas urgentes e inmediatos (las inundaciones en este caso), a la superficie de la poesía llega, en cambio, la posición ambigua ocupada por agua e

Revista Iberoamericana, Vol. LXXVIII, Núm. 241, Octubre-Diciembre 2012, $783-803$
ISSN 0034-9631 (Impreso) 
indígenas a fines del siglo xvı y principios del siglo xvII. En lo que se refiere al agua de los lagos, ésta era un medio de transporte relativamente eficaz, pero al mismo tiempo un elemento amenazante al orden de la ciudad. Respecto a los indígenas, hay que recordar que las dudas en torno a la posibilidad de transformarlos en sujetos apropiados al proyecto imperial se acentúan en esta época. El desagüe sería así un mecanismo que "administra" los recursos locales para asegurar el correcto funcionamiento de la economía. Como veremos, esta medida es resultado de la frustración y el fracaso ante sujetos que parecían impermeables a los mecanismos de “vaciado" implementados por el trabajo y la evangelización. La muerte (material, cultural) provocada por la construcción de esta novedosa tecnología es así el fundamento no enunciado de una economía que parecía transcurrir al margen de la historia y su violencia y que sin embargo, tenía en la violencia absoluta su única posibildad.

Refiriéndose a la obra de Baltasar Gracián, Bradley Nelson analiza la reorganización de la subjetividad en el momento en que ésta se desvincula de un orden trascendental a través de una transferencia del carácter regulatorio de la presencia (la "sustancia" del sujeto), a un paradigma moderno que enfatiza la actividad. Si el sistema jerárquico feudal estaba basado en la pureza de sangre (confería al individuo el estatus que le correspondía por lo que era), el que surge posteriormente hace de la actuación personal y el buen gusto, el nuevo eje (moderno, racional) a través del cual se adquiría una posición social. El emplazamiento del buen gusto y el saber como nuevos parámetros de la jerarquía se encuentra ligado a la redención de la "nada" del hombre por medio de múltiples actividades que dan forma al nuevo ser del sujeto. ${ }^{22}$ Así, dice Nelson, el sujeto moderno surge no de una reflexión en torno a una entidad consciente de sí misma, sino precisamente de lo contrario, de una "falta de ser" compensada por la actividad: el ser del sujeto moderno no sería sino un "efecto estético", resultado de las actividades que ocupan el lugar (vacante) de la ontología (82).

Como muestra Nelson, en el caso de Gracián, la auto-representación está políticamente motivada: no tiene por objeto la verdad o la sustancia, sino el poder (94). En este sentido, Nelson lee esta falta de fijeza como un proceso ligado a la voluntad de poder y la opone a lecturas celebratorias en las cuales el vacío (¿cómo interpelarlo?) representa un límite al poder del Estado (90). ${ }^{23}$ En el análisis de Nelson, por el contrario, este proceso resulta en una ofuscación de la violencia en la medida en que el sujeto que la realiza no existe ontológicamente. La violencia aparece así como resultado de un sistema abstracto, desligado de cualquier sujeto. Cuestiones como la muerte, el hambre y la violencia misma, son relegados a nombre del "buen gusto" para el cual

${ }^{22}$ En su análisis Bradley Nelson analiza los procesos que tanto en el área de la ontología, como de la epistemología dan lugar al sujeto de la modernidad. Aquí me enfoco únicamente en la cuestión ontológica.

${ }^{23}$ La lectura de Žižek en el artículo de Nelson.

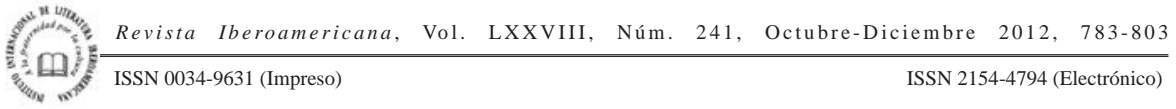


"la verdad" y "la sustancia" son desplazadas por cuestiones relativas "al gusto y la forma”. Así, la perversidad de este sistema que niega todo recurso a la interpelación, radica en la posibilidad infinita de la reiteración de la violencia y en su transformación en un problema estético: el de puntos de vista "competing and insubstantiated" (96).

Como vimos, en Balbuena el trabajo permite precisamente una reformulación de los sujetos; situación que se traduce en un nuevo orden social. El sujeto es definido por la labor que realiza, y de ella depende también su sitio en la jerarquía urbana. Sin embargo, los indios salvajes y los tributarios representaban residuos estéticos y ontológicos no modificados por la actividad económica y, por lo tanto, constituían un espacio opaco e inasimilable para un sistema que buscaba equiparar el ser con el hacer.

Hay que recordar además que este exceso es postulado en un momento de crisis en el que se multiplican las aseveraciones respecto al fracaso de los evangelizadores encargados de sustraer a los indios de su antiguo ser (su inmersión en adoraciones idolátricas) para convertirlos en sujetos cristianos. La decepción respecto a esta transformación es repetida a partir de fines del siglo xvi por personajes como Diego Durán, Bernardino de Sahagún y Jerónimo de Mendieta. En la península, ante una situación semejante, cuando se llega a dudar de la integración de moros y judíos al modelo de vida cristiano, se opta por la expulsión de estos grupos que representaban un reto al poder de interpretación e interpelación del estado (de la Flor 233-34). En el caso de la Nueva España, sin embargo, no se podía expulsar a los indios a ningún lado.

Junto al indio, cuya constitución ontológica rebasaba la determinación económica (en el caso de los indios "salvajes" no eran ni siquiera tocados por ella), se encuentra también el agua cuyo ordenamiento en un sistema hidráulico particular no había sido comprendido por criollos y españoles. Ante estos dos espacios ilegibles que amenazaban el sistema económico-social, el desagüe se presenta como una posible solución doble: por un lado, al prometer sacar del entorno un agua cuya ausencia permitiría cimientos sólidos a la ciudad; por otro, al consumir la vida indígena que la rodeaba.

Pese a las pestes que habían diezmado a la población indígena y pese al carácter necesario de este grupo para mantener funcionando el sistema económico del que dependían criollos y peninsulares, localmente los indios representaban una superabundancia -por sus números, por su naturaleza- que rebasaba la clasificación impuesta por la economía. Ralph Bauer ha señalado que el dilema de la modernidad criolla radicaba en el hecho de que, a diferencia de sus contemporáneos protestantes, ellos no había podido excluir o aniquilar a los sectores sociales que habían conquistado y de cuyo trabajo dependían (178, énfasis mío). Según Bauer la ambivalencia criolla respecto a los indígenas (y las castas), y su temor a lo que podía ocurrir con estos grupos en caso de que terminara el poder imperial, explican la estabilidad social de un sistema colonial resentido enormemente por los criollos debido al trato que recibían de los enviados de la metrópoli (162).

\footnotetext{
(3) Revista Iberoamericana, Vol. LXXVIII, Núm. 241, Octubre-Diciembre 2012, 783-803 ISSN 0034-9631 (Impreso) ISSN 2154-4794 (Electrónico)
} 
Por ello, la implementación del canal del desagüe cuya construcción implicó un elevado costo para la población indígena, ${ }^{24}$ ya porque muchos dejarían ahí la vida (ahogados o avasallados por las montañas de piedra que debían remover), ya porque su subsistencia fuera violentamente trastocada por una obra que les arrebataba el agua de la que dependían. ${ }^{25}$ Frente a esto, resulta cuando menos irónico que incluso ahora existan versiones en las cuales el desagüe es admirado como una de las mayores obras de ingeniería de su época en el mundo.

El desplazamiento de la metrópoli en tanto que hegemonía para el orden local permitió así la traslación de la guerra de conquista a ámbitos que al menos a primera vista parecerían menos problemáticos. Es el gobierno colonial local, el cabildo de criollos y peninsulares, el que a nombre de salvar la ciudad de futuras inundaciones presiona al virrey en turno para continuar y expander un proyecto de ingeniería que, sin embargo, siempre fue asumido de forma intermitente e inepta. El trabajo forzado, y la violenta interrupción que el desagüe significó para la vida indígena, desmienten cualquier pretensión de pensar el estado colonial en tanto que hegemonía: la fuerza bruta seguía siendo en el siglo xvir el mecanismo a través del cual se administraban los recursos.

Quizás en esto radique la diferencia en el proceso de acumulación originaria en las colonias respecto a las metrópolis: en la colonia no fue suficiente despojar a sus habitantes de los medios de producción para obligarlos a asumir un trabajo asalariado, ni lo fue tampoco que el trabajo fuera más bien forzado y coercitivo; en la colonia se trataba de acabar con la vida misma cuando cuando ésta era vista como excesiva. Francisco Gudiel, quien en 1555 es el primero en proponer la desecación para acabar con los problemas del agua, era precisamente un barbero dedicado a aplicar sangrías, y en el siglo XVII el ingeniero a cargo del desagüe es alabado con metáforas médicas que hablaban de la necesidad de purgar y limpiar una ciudad de sus "excesos". El equilibrio dependía de la apertura de venas que dejaran correr el dañino material que afectaba constantemente a la ciudad (Boyer 121): para asegurar la vida de algunos, era necesario dejar correr la de otros.

${ }^{24}$ Debido a que la ciudad de México se hallaba en una cuenca cerrada, y sobre el lago de Texcoco, el más bajo respecto a los otros que la rodeaban, en un primer momento el trabajo del desagüe consistió en abrir un tajo de varios kilómetros en las montañas que permitiera drenar el agua de los lagos al norte de la ciudad (Zumpango y Xaltocan) y desviar toda el agua del río de Cuautitlan de la región (este río desembocaba en los lagos al norte). En su estudio de la vida de los nahuas después de la conquista, Charles Gibson asegura que por su severidad el trabajo del desagüe fue siempre considerado excepcional. Los indios eran amarrados a postes en la orilla del agua y obligados dragar el fondo mientras los suspendían sobre la corriente. Según Gibson incluso en la colonia tardía la población indígena vivía con miedo al trabajo del desagüe (237-240).

${ }^{25}$ Gibson señala que además del enorme costo del desagüe en vidas, tiempo y dinero, éste significó la decadencia "extremadamente rápida y severa" de todas las poblaciones que iban perdiendo el agua de esta forma (6). Algunos historiadores indican que a lo largo del periodo colonial, y de forma directa o indirecta, el trabajo coercitivo del desagüe tomó la vida de cerca de un millón de indígenas (Boyer 44-45).

Revista Iberoamericana, Vol. LXXVIII, Núm. 241, Octubre-Diciembre 2012, $783-803$
ISSN 0034-9631 (Impreso) 
Si el vaciado ontológico no funcionaba en las colonias y los indios no dejaban de ser idólatras para ser cristianos, o seguían representando una forma de existencia que excedía la definición laboral, la muerte era una alternativa. Aquí no se trata de la muerte directa, obvia, de la guerra, sino del mecanismo perverso de una solución "inocente" (la tecnología) a un problema sugerido en otros lados. Desde el punto de vista de los proponentes del desagüe el único problema a solucionar eran las inundaciones, y desde el ánimo celebratorio de Balbuena, la ciudad marchaba, pese al agua bajo su delgado suelo y la "fealdad" de algunos de sus habitantes. Sin embargo, como vemos, poesía y tecnología están quizás más relacionadas de lo que podía esperarse, aunque con esto no es mi intención culpar a Balbuena y su poesía por el desagüe, sino vincular un imaginario social criollo y peninsular (el agua y los indios son, como dije, una preocupación en muchas obras de la época), con medidas que a primera vista parecen absolutamente ajenas al universo de una economía que intentaba desplazar a la historia.

Si una de las ventajas del pensamiento y la acción insubstanciadas de las que escribe Nelson es la creación de una situación en la que es imposible interpelar a una violencia que parecería autogenerada y desvinculada de cualquier sujeto -una acción en abstracto, un simple mecanismo del poder- en este análisis he tratado de conectar dicha violencia con proyectos políticos específicos. El efecto negativo del desagüe sobre la vida indígena puede verse como un producto secundario, un daño colateral, pero es también indirectamente una posible solución a los problemas que desvelaban a criollos y peninsulares viviendo en la capital de la Nueva España. La muerte es así lo que garantiza a estos grupos la continuidad de un sistema económico que ante el fracaso de las instituciones que lo sostenían (un estado colonial que no entendía la hidraúlica prehispánica y una iglesia que no convertía del todo a los indios) renuncia a la hegemonía y opone a la ontología de una presencia (indeseable, inmanejable), la violencia de un “desarrollo” tecnológico que supuestamente solucionaba problemas urbanos.

Esta economía que desechaba eso con lo que no se podía o quería vivir-millones de litros cúbicos de agua y junto con el agua, la vida de millares de indígenas que murieron trabajando en condiciones dantescas -invita a pensar en lo señalado por Georges Bataille respecto al consumir gratuito, sin capacidad de recuperación, que marca de forma distinta a distintas sociedades. Si para Bataille, la guerra y el lujo exorbitante son dos formas de un exceso que debe ser utilizado improductivamente para evitar que una sociedad se atrofie, el desagüe fue la política colonial que permitió disipar el exceso de vida que la asediaba y que según Bataille constituye el factor de ruina más peligroso en el funcionamiento de cualquier economía (24).

A decir de Bataille, una economía debe deshacerse de todo aquello (vida, energía en exceso) que no le sirva para crecer si no quiere que esta energía superabundante termine acabando con ella. En el análisis de Bataille la ontología (life-force) queda subsumida en la economía (22-23), y en un ejemplo que recuerda lo señalado por Nelson respecto

Revista Iberoamericana, Vol. LXXVIII, Núm. 241, Octubre-Diciembre 2012, $783-803$
ISSN 0034-9631 (Impreso) 
a la transformación de problemas éticos en una cuestión estética, Bataille asegura que el juicio sobre el sistema económico que equilibra la producción y disipación de energía, depende de puntos de vista particulares (39). ${ }^{26}$ Tal vez por ello, pese a los costos de su realización, hay todavía personas para quienes es importante enfatizar la hazaña tecnológica del desagüe.

Ya que los miembros del cabildo no estaban dispuestos a terminar con el status quo, había que desechar esa energía excesiva, en un mecanismo de auto-preservación ciega (salvarse criollos y peninsulares, su ciudad y el sistema económico que los beneficiaba) que implica el consumo más absurdo y fantástico y la reinstauración del sacrificio. Aunque en este caso se trata de un sacrificio étnicamente determinado (eran indios quienes trabajaban en el desagüe) y constituido como mecanismo secularizado y tecnificado, aparentemente libre de toda polémica histórica.

Es en este sentido que el desagüe es la economía de la economía, es decir, el sistema de administración de recursos que permitía la consolidación del sistema económico mercantil y capitalista en la capital de la Nueva España. Sin embargo, las constantes inundaciones que siguen asolando a la ciudad de México son un recordatorio de otro tiempo y otro espacio que quizás persiste pese a la violencia y la continuidad de una colonización sistemática.

\section{BiBLIOGRAFÍA}

Agostoni, Claudia. Monuments of Progress: Modernization and Public Health in Mexico City, 1876-1910. Boulder: UP of Colorado, 2003.

Aréchiga Córdoba, Ernesto. "El desagüe del Valle de México, siglos XVI-XXI. Una historia paradójica”. Arqueología mexicana 12/68 (2004): 60-65.

Arnold, Philip. Eating Landscape. Aztec and European Occupation of Tlalocan. Boulder: UP of Colorado, 1999.

Balbuena, Bernardo de. Grandeza Mejicana. Guadalajara: Gobierno del Estado de Jalisco, 1989. Siglo de Oro en las selvas de Erífile. Madrid: Ibarra, Impresor de Cámara de SM, 1821.

\footnotetext{
${ }^{26}$ Hay que recordar que Georges Bataille escribe The Accursed Share en el contexto del Plan Marshall, de manera que el libro puede ser entendido como un sofisticado análisis que asegura a los Estados Unidos la coherencia de salvar a Europa invirtiendo ahí su surplus como un medio que también contribuiría a crear en Europa un amortiguador contra la posible expansión rusa. Si la superabundancia no era racionalmente utilizada, recuerda Bataille a los norteamericanos, podía llevarlos a la catástrofe. Lo que persigue Bataille es la reinstauración del status-quo internacional -la continuidad del diferencial de poder entre las distintas naciones del mundo- pese a la catástrofe de la guerra. No se le ocurre que Estados Unidos podía disipar su exceso económico en otros sitios, por ejemplo.
}

\footnotetext{
Revista Iberoamericana, Vol. LXXVIII, Núm. 241, Octubre-Diciembre 2012, 783-803 ISSN 0034-9631 (Impreso) 
Barrera, Trinidad. "Entre la realidad y la exaltación: Bernardo de Balbuena y su visión de la capital mexicana”. Poéticas de la restitución: Literatura y cultura en Hispanoamérica colonial. Raúl Marrero-Fente, ed. Newark: Cuesta, 2005. 73-82.

Bataille, Georges. The Accursed Share. An Essay on General Economy. Volume I: Consumption. Nueva York: Zone Books, 1988.

Bauer, Ralph. The Cultural Geography of Colonial Latin American Literatures. Cambridge: Cambridge UP, 2003.

Boyer, Richard E. La gran inundación. Viday sociedad en México(1629-1638). México: Secretaría de Educación Pública, 1975.

Gómez, Fernando. "Estética manierista en los albores modernos de la periferia colonial americana: acerca de la 'Grandeza mexicana' de Bernardo de Balbuena (15621627)”. Hispanic Review 71/4 (2003): 525-548.

Fanon, Frantz. The Wretched of the Earth. Nueva York: Grove Press, 1963.

Flor, Fernando R. de la. "Sacrificial Politics in the Spanish Colonies". Reason and Its Others. Italy, Spain, and the New World. David R. Castillo y Massimo Lollini, eds. Nashville: Vanderbilt UP, 2006. 243-258.

Foucault, Michel. “Of Other Spaces”. Diacritics 16 (Spring 1986): 22-27.

Fuchs, Barbara y Yolanda Martínez-San Miguel. "La grandeza mexicana de Balbuena y el imaginario de una 'metrópolis colonial'”. Revista Iberoamericana 75/228 (2009): 675-695.

Gibson, Charles.The Aztecs Under Spanish Rule. A History of the Indians of the Valley of Mexico 1519-1810. Stanford: Stanford UP, 1964.

Larraz, José. La época del mercantilismo en Castilla, 1500-1700. Madrid: Aguilar, 1963.

Marx, Karl. Capital. A Critique of Political Economy. Vol. 1: The Process of Capitalist Production. Chicago: Charles H. Kerr \& Company, 1908.

"Third Manuscript from 1844". Collected Works. Vol. 3. Karl Marx y Frederick Engels. 1843-1844. Londres: Lawrence and Wishart, 1975. 290-346.

Mathes, Michael. "To Save a City: The Desagüe of Mexico-Huehuetoca, 1607”. The Americas 26/4 (1970): 419-438.

Nelson, Bradley. “A Ritual Practice for Modernity: Baltasar Gracián’s Organized Body of Taste”. Reason and Its Others. Italy, Spain, and the New World. David R. Castillo y Massimo Lollini, eds. Nashville: Vanderbilt UP, 2006. 79-100.

Palerm, Ángel. "Obras hidraúlicas prehispánicas en el sistema lacustre del Valle de México”. México prehispánico. Ensayos sobre evolución y ecología. Carmen Viqueira, ed. México: Consejo Nacional para la Cultura y las Artes, 1990. 185-443.

Pardo, Osvaldo. "Giovanni Botero and Bernardo de Balbuena: Art and Economy in La grandeza Mexicana”. Journal of Latin American Cultural Studies 10/1 (2001): 103-117.

Pascual Buxó, José. "Bernardo de Balbuena: el arte como artificio”. Homenaje a José Durand. Luis Cortes, ed. Madrid: Verbum, 1993. 189-215.

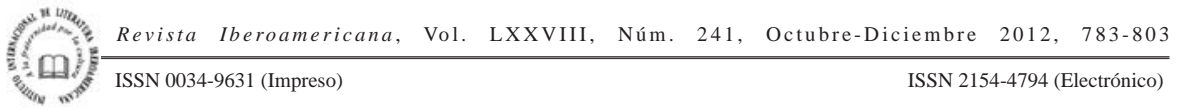


Rama, Ángel. “Fundación del manierismo hispanoamericano por Bernardo de Balbuena”. University of Dayton Review 16/2 (1983): 13-22.

Tortella, Gabriel and Comín, Francisco. "Fiscal and Monetary Institutions in Spain (1600-1900)". Transferring Wealth and Power from the Old to the New World. Monetary and Fiscal Institutions in the $17^{\text {th }}$ through the $19^{\text {th }}$ centuries. Michael D. Bordo y Roberto Cortés Conde, eds. Cambridge: Cambridge UP, 2001. 140-186.

Valle W., Ivonne del. “On Shaky Ground: Hydraulics, State Formation and Colonialism in Sixteenth-Century México”. Hispanic Review 77/2 (2009): 197-220.

Revista Iberoamericana, Vol. LXXVIII, Núm. 241, Octubre-Diciembre 2012, 783-803 ISSN 0034-9631 (Impreso) ISSN 2154-4794 (Electrónico) 
